\title{
Fashion Mix: uma exposição sobre a contribuição dos imigrantes para a moda parisiense ${ }^{1}$
}

Fashion Mix: the exposition about the contribution of the immigrants to the parisian fashion

\section{palavras-chave}

\section{moda; museus; imigração; capital da moda.}

[abstract] The exhibit Fashion Mix, mode d'ici, créateurs d'ailleurs, heldatthe Musée de l'Histoire de I'Immigration, Paris, from December/2014 to June/2015, reflects the organizing effort to articulate fashion andim migration subjects. The show exhibited haute couture clothes signed by immigrated designers, who contributed to consolidate Paris as the "capital of fashion". The exhibit's proposal was to remind visitors the importance of immigration to the French fashion industry. The purpose of this article is to expatiate about the exhibition through its narrative, considering the complex scenario of immigration in France.

[keywords] fashion; museums; immigration; capital of fashion. 


\section{Introdução}

0 Palais de la Porte Dorée, edificação art déco erguida nos anos 1930, é o prédio que abriga o Musée de l'Histoire de I'Immigration, um espaço que apresenta dois séculos da história da imigração na França. Ao alcançarmos a exposição permanente denominada Repères, no terceiro piso, seguimos pelo lado direito até 0 fundo, onde fica o grande salão com uma parte reservada às mostras temporárias. Nele, entre 9 de dezembro de 2014 e 28 de junho de 2015, ocorreu a Fashion Mix, mode d'ici, créateurs d'aillieurs, uma exposição idealizada e organizada pelo Musée de l'Histoire de l'Immigration juntamente com o Musée de la Mode de la Ville de Paris, Palais Galliera. A propósito de suas concepções museais, são dois museus com diferentes propostas. 0 primeiro, dedicado a contar a história da imigração na França e, o segundo, munido inicialmente de uma coleção de 2 mil peças de roupas vindas do Musée Carnavalet, foi constituido para consolidar o papel de Paris como a capital da moda.

De acordo com os organizadores da Fashion Mix, os temas moda e imigração foram articulados com o objetivo de mostrar como a indústria da moda na França foi construida, em parte, por criadores estrangeiros. A grande maioria das peças exibidas veio do Musée de la Mode de la Ville de Paris, Palais Galliera, cuja reserva técnica, segundo o seu gestor Alexander Samson, hoje ultrapassa 300 mil itens entre peças de vestuário e documentação ${ }^{3}$.

No atual panorama europeu,em que a imigração vem sendo tema de conversas informais nos cafés e nas redes sociais, o Musée de l'Histoire de l'Immigration tem por objetivo oferecer ao público algum conhecimento sobre a história da imigração na França por meio de objetos e histórias de vida ou da combinação de ambos. Na Sala de Dons, uma seção do Palais de la Porte Dorée, estão expostos objetos doados pela coletividade, cujas histórias de vida ligam essas peças a um relato de imigração. Além de itens de afeto, fotografias e documentos, há filmes que mostram testemunhos e obras de arte que retratam, de alguma forma, os deslocamentos humanos e algumas de suas motivações.

Todos esses elementos combinados perfazem a narrativa das exposições e 0 consequente esforço de construir o conhecimento sobre o tema. Gonçalves (2007) observa que, ao visitarmos uma exposição, não nos damos conta de todo o envolvimento que há por trás daquela narrativa: a escolha dos objetos, as fontes, a classificação, os esquemas de preservação e conservação dos objetos. 0 autor reflete sobre o papel dos museus como "locus do cruzamento de uma série de relações de ordem epistemológica, social e política (...)" (GONÇALVES, 2007, p. 23). 0 papel declarado dos museus é ser um espaço de produção de conhecimento (JORDANOVA, 1989; DIAS, 1994; GONÇALVES, 2007), posicionando-se, para o visitante, como fonte de aprendizado e descobertas. Os museus, no entanto, figurando entre as opções de lazer, têm suas narrativas apreendidas de forma lúdica pelo público.

Três aspectos destacados por Jordanova (1989) definem a relação de construção do conhecimento estabelecida entre visitante e museu. 0 primeiro deles trata do olhar do visitante para o objeto exposto. Esse olhar demanda um processo de interação, no qual organizadores e curadores buscam acionar a memória e a subjetividade de quem observa. 0 segundo aspecto apontado pela autora trata das tecnologias de exibição. Por fim, ela destaca a classificação, um exercício privilegiado nos museus, uma vez que o modo como os objetos expostos são ordenados e classificados é um convite ao visitante para construir significados e realizar sua experiência no sentido lógico planejado pelos idealizadores.

0 texto que se segue pretende descrever o modo como objetos e técnicas de exposição foram programados e constituiram uma narrativa sobre os temas da moda e da imigração na exposição temporária Fashion Mix. 
0 trabalho de campo que dá suporte a este texto contou com a visita à Fashion Mix e inúmeras outras ao Palais de la Porte Dorée, em seus diversos espaços (exposições temporárias e permanente, Sala de Dons, foyer e midiateca). Ainda fazem parte do corpus empírico o catálogo da exposição Fashion Mix e as entrevistas com Isabelle Renard, responsável pelas coleções de arte contemporânea do Musée de l'Histoire de I'Immigration, e Alexandre Samson, assistente de Olivier Saillard, comissário geral da exposição Fashion Mix e diretor do Musée de la Mode de la Ville de Paris, Palais Galliera. Esta última entrevista ocorreu no $11^{\text {eme }}$ arrondissement ${ }^{4}$, no espaço da reserva técnica desse museu da moda.

Isabelle Renard afirma que o objetivo maior do museu que se dedica à imigração é mostrar ao público que "I'histoire de l'immigration, c'estaussil'histoire de la France" ${ }^{15}$. Corroborando essa afirmação, a Fashion Mix procurou mostrar que a imigração também escreveu boa parte da história da moda francesa, contribuindo para consolidar o epiteto de Paris, capital da moda.

Neste texto, em primeiro lugar, será feita uma descrição do Musée de l'Histoire de I'Immigration, destacando os aspectos relacionados com suas implicações no cenário político francês, bem como uma descrição da sua exposição permanente denominada Repères (referências). Com essa seção, o que se pretende é situar o leitor acerca dos debates envolvidos na questão da imigração em território francês e da própria concepção do museu como um espaço destinado a valorizar os aportes econômicos e culturais trazidos por diferentes grupos migratórios. Na segunda seção, será feita uma digressão acerca do epíteto capital da moda, na qual o contraponto se dá pela reflexão sobre os estrangeiros que contribuíram para que a capital da moda seja, reconhecidamente, a cidade de Paris. Dado esse contexto, a seção seguinte trará a descrição da Fashion Mix, os nomes escolhidos para representar a imigração na cidade de Paris e como foram classificados. As duas últimas seções colocarão algumas observações sobre o tema, seguidas das considerações finais, consolidando os aspectos abordados ao longo do texto.

\section{Le Musée de l'Histoire de l'Immigration}

Erguido no número 293 da AvenueDaumesnil, em Paris, o edifício conhecido como Palais de la Porte Dorée foi projetado pelo arquiteto Albert Laprade e, desde 2007, abriga o Musée de l'Histoirel'Immigration. 0 tema dos deslocamentos territoriais é de grande complexidade, sobretudo na França, um pais que, apesar de haver adotado políticas de imigração em diversos periodos de sua história, tem, na sua concepção de nacionalismo, um modelo que, para Noiriel (2001), formou o substrato ideológico que serviu para o que esse autor chama de "a invenção do 'problema' da imigração". Afinal, em dadas condições, a imigração, longe de ser um "problema", foi, ao contrário, estimulada pelo Estado francês.

Como exemplo, convém citar o déficit de mão de obra, em um quadro mundial de industrialização no século $\mathrm{XIX}$, que abriu espaço para uma das grandes vagas migratórias que desembarcaram na França. Noiriel (2005) recorda que 0 êxodo rural, condição para o crescimento urbano e industrial, encontrou a resistência dos campesinos à mudança no estilo de vida deles. Assim, a industrialização francesa, em sua gênese, deve seu impulso à imigração. 0 mesmo autor ainda reporta a estimativa de que $10 \%$ da mão de obra francesa foi liquidada graças às grandes guerras e seus desdobramentos, demandando mais um aporte de trabaIhadores de outros territórios, até mesmo para a reconstrução do país, motivo pelo qual novas vagas de imigrantes chegaram pelo porto de Marselha.

0 discurso midiático dedicado ao museu deu destaque à celeuma política que se instalou em torno da sua criação e se constituiu em um indício da proposição de Noiriel sobre como a imigração se converteu em um "problema". Gruson (2011) se posiciona como crítico de uma mídia que, segundo ele, não faz mais 
do que instrumentalizar o tema da imigração, o que contribui para consolidar a ideia de um fenômeno "problemático".

Criado com o objetivo declarado de levar ao público em geral, notadamente aos franceses, conhecimento sobre a importância da imigração para a formação do pais, o museu é objeto de disputas politicas desde a sua idealização, em 2002, quando o então presidente Jacques Chirac tomou a iniciativa de concebê-lo. Isso ocorreu em um momento em que a extrema direita nacional, o partido Front National, representada pelo candidato à presidência da república francesa Jean-Marie Le Pen, ganhou terreno nas eleições de 2002. Esse partido é duramente criticado por aqueles que condenam os discursos de alteridade. Entre eles, Emmanuel Todd (1994), para quem o partido é o responsável pela "demonização" dos movimentos migratórios na França.

Em 2007, o então presidente Nicolas Sarkozy, recém-eleito representando a direita francesa pelo seu partido, o Union pourunMouvementPopulaire (UMP), menos radical que o Front National, decidiu não ir à abertura do museu. Alguns órgãos da imprensa francesa (entre eles, a France TV Info e a France 24, canal de notícias, por exemplo) noticiaram que o então presidente "ignorou" o museu6. Esse governo criou o Ministério da Imigração e Identidade Nacional, o que provocou o repúdio e o consequente pedido de demissão de historiadores e outros intelectuais que, na ocasião, gestavam o projeto original do museu. Eles alegaram que o título do ministério (sublinhando a expressão "identidade nacional") seria um tônico a dar robustez ao sentimento de alteridade e ao preconceito contra imigrantes. Somente em 2012, um presidente francês visitou o museu, François Hollande, recém-eleito pelo Partido Socialista.

$\mathrm{Na}$ França, atualmente um país com uma população imigrante estimada em 5,9 milhões de pessoas ( $8,9 \%$ do total de habitantes no território francês), a equação que se desenha, com uma direita política que se posiciona de modo crítico em relação aos movimentos migratórios e com vozes da esquerda que buscam a incorporação desses imigrantes à sociedade francesa, é de grande complexidade. 0 tema engendra implicações que vão desde a forma como os estrangeiros entram no pais - se chegam por vias legais ou clandestinas - até o segmento social ao qual o imigrante pertencia em seu território de origem. Ou seja, o conjunto de capitais que esses individuos portam ao chegar ao pais que os acolhe, passando, evidentemente, pelo pânico disseminado pela Europa em relação aos refugiados e os últimos episódios de massacres e atentados reivindicados por grupos fundamentalistas de origem estrangeira.

\section{A exposição permanente Repères (Referências)}

A narrativa da exposição permanente destaca as contribuições culturais, políticas e econômicas dos imigrantes para o país, mas também todas as implicações e complicações desses deslocamentos, tais como as negociações com 0 Estado francês, as burocracias para se estabelecer em um território estrangeiro, as boas-vindas e a hostilidade enfrentadas no cotidiano, a distância e 0 apego ao território natal e a dura busca por colocação profissional e moradia.

Com as imagens e os testemunhos de superação e enfrentamento de adversidades durante o percurso e o cruzar de fronteiras, a exposição permanente Repères termina por retratar a figura do imigrante como um personagem angustiado, desprovido de recursos e que enfrenta inúmeros desafios, a começar pelas questões que o moveram a deixar seu pais de origem. Esses 
pontos são comumente elencados como guerras, fome, crises econômicas e perseguições políticas, entre outros motivos relacionados às mazelas vividas no território que ficou para trás. Há pouco destaque para o perfil do imigrante que chega ao país como investidor, como integrante de uma elite cultural e econômica, tal como descreve Nancy Green sobre uma classe privilegiada de norte-americanos que foram à França para "vender" a modernidade norte-americana (2002), ou apenas pelo fascínio que a França e, em especial, a cidade de Paris, exerce em muitos indivíduos. Ao fim, a narrativa da exposição permanente oferece poucas nuances ao apresentar ao público a imagem do imigrante. Gruson (2011) pondera que a complexidade de se concretizar um projeto cultural sobre imigração, um fenômeno multiforme, é o grande desafio museográfico da instituição.

A exposição permanente busca ainda mostrar reconhecimento pelas contribuições da imigração. A instalação situada no largo corredor do lado esquerdo da entrada, por exemplo, destaca os objetos que passaram a fazer parte da cultura francesa graças à contribuição dos imigrantes. Entre eles, chama atenção a sacola de plástico trançada, confeccionada com material resistente e de baixo custo utilizada por aqueles que deixaram o seu pais. 0 painel, por meio de texto e imagens, conta como a sacola popular tornou-se item de distinção depois de ser exibida em um desfile do estilista Marc Jacobs, ele mesmo um estrangeiro em território francês.

Seguindo pelo lado esquerdo da entrada, em painéis com cobertura de vidro, começamos a encontrar nomes de imigrantes notáveis que chegaram à França. Lá estão a norte-americana Gertrude Stein, o espanhol Pablo Picasso, o alemão Walter Benjamin e um nome expressivo do campo da moda, o espanhol Cristóbal Balenciaga -.um dos criadores reverenciados na Fashion Mix, como veremos em outra seção deste artigo. Antes, porém, é necessária a digressão sobre o epiteto de Paris, capital da moda.

\section{Paris, capital da moda}

Percorrer a história da moda nos leva inevitavelmente à cidade de Paris. Benjamin (1969), entre as décadas de 1930 e 1940, analisou, sob a ótica marxista, 0 papel das exposições internacionais ocorridas no século XIX, importantes catalisadoras da consolidação da imagem de Paris como a capital da moda e do luxo. 0 autor ressalta que a moda prescreve rituais em que o fetiche da mercadoria é valorizado e enaltecido, especialmente por causa dos recursos de fantasia que foram, notadamente, exibidos nas Exposições Universais a partir de 1867.

Assim, descrita por Benjamin no início do século XX como a "capital da moda e do luxo", Paris é cosmopolita e destino de muitos projetos migratórios. Na relação da "capital da moda" com a imigração, é possível identificar um movimento dialógico. De um lado estão os estrangeiros que contribuiram fortemente para a consolidação dessa relação entre Paris e a moda, como é o caso exemplar do britânico Charles Frederick Worth, de outro, há os que, atraídos por essa relação já consolidada, buscaram seu espaço na capital da moda, beneficiando-se, mas também contribuindo para a consolidação do papel que parece ser destinado à capital francesa.

0 texto do quadro final da exibição Fashion Mix revela que, nos desfiles ocorridos em Paris no ano de 2014, 114 dos 164 estilistas eram de origem estrangeira. Isso sintetiza a mensagem que a narrativa da exposição oferece ao público: Paris é a capital da moda, atraindo criadores imigrados que também são os tijolos que contribuem para a construção desse epiteto. Essa mensagem é reafirmada por Renard e Samson em entrevista a esta autora, e por Saillard em entrevista a Poinsot para o periódico Hommes \&t Migrations (2015). 


\section{O que fez de Paris a capital da moda?}

Para Saillard, em entrevista a Poinsot (2015), a tradição francesa no mundo da moda vem do século XVIII, começando por uma promissora produção têxtil e por mercadores de moda, tal como Madame Rose Bertin, para mencionarmos uma bastante célebre. "La frivolité est diffusée en France, à Paris plus qu'ailleurs", observa Saillard (2015, p. 55).

Um marco importante na construção desse epiteto é o reinado de Luís XIV, entre 1661 e 1715. Seu padrasto, o cardeal Mazarini, o convenceu da importância do luxo e da aparência como instrumentos de governabilidade. Não por acaso, foi durante o reinado de Luis XIV que o ministro Jean-Baptiste Colbert impulsionou, por meio de incentivos do Estado, uma promissora produção de artigos de luxo, incluindo o vestuário. Por isso, DeJean (2010) marca o "nascimento da moda moderna" no ano de 1670, ainda durante o reinado de Luís XIV, situando, inclusive, nesse período, o embrião do que se pode denominar alta-costura. É um momento em que as elites europeias tomam como referência para a escolha do que vestir o que quer que estivesse sendo desenvolvido no cenário da moda parisiense.

Williams (1982) destaca o fato de que o padrão de consumo, especialmente no que se refere ao vestuário da nobreza, tenha sobrevivido à destruição da corte francesa no século XVIII. A autora argumenta que isso se deu porque costureiras e alfaiates que serviam à nobreza abriram estabelecimentos privados para atender o público em geral, o que se vê comumente na Paris da década de 1790.

A figura de Charles Frederick Worth, que abre a Fashion Mix, surgiu apenas um pouco mais tarde, precisamente, em 1845, ano de sua chegada à cidade. As entrevistas e referências encontradas sobre Worth nos oferecem pistas que nos deixam entrever uma atração do costureiro pelo mundo da moda antes ainda de sua chegada.

\section{A capital da moda a partir de Charles Frederick Worth}

Se Paris constrói sua reputação como capital da moda desde o século XVII, por que então Charles Frederick Worth é quem marca esse momento, sendo o ponto de partida da exposição Fashion Mix?

Segundo Saillard, em entrevista a Poinsot (2015), ainda antes de mudar-se definitivamente para Paris, Worth trabalhou com tecidos, adquirindo conhecimento técnico e refinando o que o diretor do Palais Galliera denomina como "senso de marketing" (p. 55). A contribuição do costureiro inglês foi a invenção da alta-costura como ela é reconhecida nos dias de hoje: a forma mais luxuosa da confecção do vestuário. A aura de arte se alia a um tratamento comercial. Ele incorporou ao sistema os desfiles sazonais e a etiqueta com seu nome no forro dos seus vestidos.

Laver (1989) recorda que Worth caiu nas graças da imperatriz Eugenie, esposa de Napoleão III. Ao contrário do que se propunha naquela época, a cliente não opinava, mas confiava nas recomendações do costureiro. É o início do período da moda impositiva e do "criador demiurgo", para usar a expressão de Lipovetsky (1989, p. 92).

Segundo DeJean (2010), a alta-costura francesa já era uma indústria pujante na época em que o inglês Worth aparece no cenário da moda parisiense. Até então, a moda na capital francesa era um campo de trabalho mínimo e mais colaborativo. Worth marca a entrada masculina na área e modifica o sistema.

Mais do que a contribuição efetiva de Worth para o mundo da moda francesa, o que está em jogo na narrativa da exposição Fashion Mix é o fato de um 
estrangeiro, um inglês, ter obtido um lugar privilegiado no panteão da moda na cidade que, desde o século XVII, era referência nesse campo.

\section{As outras capitais da moda}

Ao ser indagada sobre a inspiração para o nome da exposição Fashion Mix (em inglês), Renard nos remete ao evento mais importante da moda na atualidade, a Fashion Week, que ocorre duas vezes por ano nas cidades de Nova York, Londres, Milão e Paris.

Uma das inovações de Worth no campo da moda foi a organização de desfiles com "sósias". Outra britânica, Lady Duff Gordon (também homenageada na exposição Fashion Mix) passou a promover desfiles com formato de espetáculo: com data fixa, programa distribuído aos clientes e música durante a passagem das manequins (BARTHIER, 2013/14). Nos anos 1930, portanto, imediatamente após o início da crise da alta-costura na França, a Chambre Syndicale de laCouture regulamentou a prática criada por Lady Gordon, com calendário e fixação de regras de apresentação.

A Fashion Week, em sua forma moderna, nasceu em Nova York no ano de 1943. A ocupação alemã em Paris impediu que os jornalistas norte-americanos viajassem para a capital francesa para cobrir o lançamento das novas coleções, o que levou a jornalista Eleanor Lambert a montar a Fashion Weekem Nova York, privilegiando nomes do cenário norte-americano (BARTHIER, 2013/14).

0 mercado se expandiu e outras capitais da moda surgiram. A agência norteamericana Global Language Monitor avalia anualmente a repercussão dos desfiles de moda mais importantes no mundo ${ }^{9} \mathrm{e}$, assim, define e anuncia a cidade que se tornou capital da moda. Para ficarmos nas medições mais recentes, em 2011, 2012 e 2013, a eleita foi Londres. Em 2014, foi Nova York. Paris ficou em segundo lugar. Finalmente, em 2015, aparece na dianteira no ranking da agência, que publica suas medições desde 2008.

A despeito do trabalho da agência e da incorporaçãode outras capitais (inclusive Rio de Janeiro e São Paulo), Barthier (2013/14) opina que Paris segue como a capital da moda nos corações e nas mentes.

\section{Fashion Mix, mode d'ici, createurs d'ailleurs}

A exposição Fashion Mixfoi dividida em dois grandes blocos, sendo o primeiro deles intitulado Du milieu du XIX emesiécle jusqu'auxan nées 1960 (da metade do século XIX aos anos 1960), e o segundo, De lafin desan nées 1970 a aujourd'hui (do fim dos anos 1970 aos dias de hoje). Cada um foi classificado em seções.

A primeira seção do primeiro bloco começou com Charles Frederick Worth. Ele foi o nome de destaque da L'école britanique, seguido por outros criadores de origem britânica: Edward Molyneux, Alexander McQueen, Phoebe Philo, Vivienne Westwood, Lady Duff Gordon, John Galliano, Charles Poynter, ClareWaight Keller e Jean Muir.

A exposição continuou com a seção Recherchessurlestissus (pesquisas sobre tecidos), que teve como nome de destaque o japonês IsseyMiyake. Seguiram-se a ele 0 espanhol Mariano Fortuny, a espanhola nascida nos Estados Unidos SybillaSorondo, o italiano Romeo Gigli, o austriaco Christoff von Drecoll, o alemão Gustave Beer, o norte-americano Main Rosseau Bocher, a ucraniana Sonia Delaunay, o belga Dries van Noten, a russa Natalia Gontcharova, a polonesa Lola Prusac, o holandês Charles Montaigne, o casal russo Irina e Felix Yusupov e a russa Maria Pavlovna. Nesta seção, a narrativa concentrou-se nas inovações técnicas. Destacaram-se o trabalho de Mariano Fortuny, engenheiro de formação que criou o tecido de seda plissada, dando origem ao modelo denominado Delfos, por sua referência às vestes gregas, e o da grã-duquesa russa Maria Pavlovna, fundadora da maison Kitmir, especializada em bordados e fornecedora para grandes grifes 
francesas, como Maison Chanel. Miyake sobressaiu-se pela inovação de seus tecidos pregueados, denominados platspeats.

A seção seguinte retomou a visibilidade da origem dos criadores. 0 nome de destaque foi Elsa Schiaparelli, iniciando a L'école italienne. Seguiram-se a ela, Valentino Garavani, Riccardo Tisci, Romeo Gigli, Popy Moreni, Véra Boréa, Pierpaolo Piccioli \&t Maria Grazia Chiuri e Maurizio Galante.

Os espanhóis vieram logo após, com Cristóbal Balenciaga abrindo a seção L'école espagnole. Depois dele, Sybilla, Paco Rabanne, Antonio del Castillo e Rafael Lopez Cebrián.

No final do primeiro bloco, estava a seção Haute couture cosmopolite des années 1950 (alta-costura cosmopolita dos anos 1950). Nela não havia exatamente um nome de destaque. Iniciava com o suiço Robert Piguet, seguido de Jean Dessès (nascido no Egito e filho de pais gregos), do libanês Rabih Kayrouz, da romena Ara Frenkian, da húngara Catherine de Karolyi e de Sarkis der Balian (nascido no território da Armênia em 1909).

0 segundo bloco, denominado De la fin des années 1970 a aujourd'hui (do fim dos anos 1970 aos dias de hoje), começou com a seção que celebrava os criadores japoneses. Miyake era o destaque, seguido de Tokio Kumagaï, Kenzo Takada, Rei Kawakubo, Junya Watanabe e Yohji Yamamoto.

A escola belga vinha logo após e foi representada pelos seguintes criadores: Martin Margiela, Olivier Theyskens, Jurgi Persoons, A.F. Vandervorst, Ann Demeulemeester, Dirk van Saene, Raf Simons e Veronique Branquinho.

A última seção, dedicada aos criadores contemporâneos, chamava Le fois sonn ement du trés contemporain (a abundância do contemporâneo). Os nomes que a integravam eram: Viktor \& Rolf e Iris van Herpen da Holanda, Alber Elbaz de Israel, Azzedine Alaïa da Tunisia, Marc Jacobs dos Estados Unidos, Karl Lagerfeld da Alemanha, Helmut Lang da Áustria, Kostas Murkudis da Alemanha, Patrick Kelly dos Estados Unidos, Walter Van Beirendonk da Bélgica, Bernhard Willhelm da Alemanha, Haider Ackermann da Colômbia, Carol Lim\&t Humberto Leon (ela, norte-americana de origem coreana, e ele, peruano), Manish Arora da İndia, GarethPugh da Inglaterra, Rick Owens e Thom Browne, ambos dos Estados Unidos.

Ao todo, a exposição apresentou mais de 70 criadores e 110 peças, entre vestuário, documentos e fotografias. 0 catálogo da mostra, no entanto, enumera por nacionalidade e ordem cronológica 270 nomes originários de 50 diferentes paises que contribuiram para a construção da capital da moda. Entre tantos nomes, como foram selecionados os criadores e as peças expostos ao público?

Sobre os criadores, Samson, ao elaborar a coleção que seria apresentada na exposição Fashion Mix, levou em consideração uma diferença significativa entre o público que visita o Palais Galliera, um museu dedicado à moda, e o do Palais de la Porte Dorée, voltado para a história da imigração. 0 do primeiro, na sua opinião, é "iniciado" no mundo da moda. Por isso, para a Fashion Mix, foram escolhidos alguns nomes emblemáticos, mais facilmente reconhecidos pelo grande público, para ancorar cada seção. 0 mesmo se aplica às peças. Elas deveriam mostrar claramente os traços e o estilo do seu criador. 
Para nós, não é exatamente um público de moda, não há uma cultura de moda (tradução livre da autora).

Biografias, mais do que objetos, foram evidenciadas. Os organizadores não esperavam dos visitantes do Palais de la Porte Dorée a mesma reação de alguém "iniciado" no mundo da moda, ao ver de perto, por exemplo, uma criação de Worth.

Observa-se ainda, na fala de Samson, que a elaboração da exposição comportou uma equação considerando a narrativa desejada, a disponibilidade de peças da reserva técnica do Palais Galliera e o estado de conservação das peças escoIhidas para representar cada criador. Não havendo disponibilidade de uma em bom estado de conservação e assinada por um dos nomes escolhidos, o plano da narrativa era alterado.

A disponibilidade de peças que perfazem a narrativa desejada é, então, um desafio. 0 Palais Galliera recebe doações e adquire roupas de grandes maisons de moda. Entre outras fontes de aquisição, segundo Samson, a instituição conta com a colaboração da revista Vogue que, por meio de um evento anual, destina cerca de 200 mil euros para essas compras. Conservar e recuperar uma peça de vestuário exige um protocolo de operações que, dependendo do estado em que está, poderá representar um investimento não programado. Esse é um dos motivos pelos quais muitas doações são recusadas. Samson acredita que rejeita quase metade das intenções de doação. No caso específico da Fashion Mix, ele lamentou que algumas peças mais emblemáticas de alguns criadores não estivessem em boas condições para a apresentação pública.

A reserva técnica do Palais Galliera, como explicou Samson, é dividida em sete grandes reservas. São agrupadas peças do século XVIII, e divididas por gênero. 0 mesmo ocorre com 0 agrupamento do século XIX. A partir desse período, a noção de criador começa a se destacar e tomar a frente na ordem de classificação, tendo, no entanto, o nome da grife como prioridade classificatória. Seria, por exemplo, o caso de tomar o nome Comme des Garçons, pela sua criadora, Rei Kawakubo. Ainda há uma preocupação com o estado de fragilidade de uma ou outra peça - isso também é levado em conta para efeito de organização das roupas na reserva técnica.

No que se refere aos criadores escolhidos para representar cada etapa da exposição Fashion Mix, pode-se agregar, além da disponibilidade e do estado de conservação de suas criações, suas biografias e a relação que têm ou tiveram com a moda e com a cidade de Paris. Os perfis são diversos, com diferentes motivos para empreender o deslocamento em direção à capital francesa. 0 trabalho de levantamento biográfico foi atribuido à equipe do Musée de l'Histoire de I'Immigration. 0 catálogo revela muitas histórias que também estão nos textos que acompanhavam as roupas e nos documentos exibidos na Fashion Mix.

Com o enfoque no tema da imigração, foi feito, para este trabalho, um rastreamento pela internet com questões pontuais: o que moveu cada um dos projetos migratórios, 0 ano de chegada à capital francesa e a origem familiar. Embora os 70 nomes tenham sido facilmente encontrados, responder às questões não foi uma tarefa muito simples. Os sites de busca nos abrem inúmeras páginas dedicadas a muitos desses criadores, mas o conteúdo, em geral, está voltado ao seu estilo, às suas influências e referências, às celebridades que usaram publicamente suas criações. Há pouco ou quase nada sobre cada trajetória pessoal, e menos ainda sobre sua condição de imigrante. Sobre os nomes mais recentes, há ainda menos.

A maior parte dos que chegaram a Paris foi atraída pelas condições que 0 campo da moda oferece na cidade. Desejando obter sucesso na carreira, os criadores perceberam a necessidade de uma ligação com a capital da moda. Paris é 
passagem obrigatória para os que trabalham e se interessam pelo tema moda. Muitos, como Alexander McQueen (Givenchy), Phoebe Philo (Chloé), John Galliano (Givenchy), Riccardo Tisci (Givenchy) e ClareWaight Keller (Chloé), com carreiras em ascensão, foram motivados por convites recebidos de grifes com sede na capital francesa. Outros, como Vivienne Westwood, Lady Duff Gordon, Charles Poynter e Rei Kawakubo, foram abrir filiais de suas marcas, já consolidadas em seus países de origem. Há, no entanto, histórias peculiares, como a do casal russo Irina e Felix Yusupov, integrantes da aristocracia russa. Eles chegaram a Paris com status de refugiados no ano de 1919 e, em 1924, criaram a casa de costura Irfe. Balenciaga e Paco Rabanne deixaram para trás o regime franquista. Rabanne contava com apenas 5 anos quando abandonou a Espanha, após o fuzilamento de seu pai. Há ainda histórias empreendedoras, como a de Vivienne Westwood, filha de um sapateiro. Seu trabalho como criadora ganhou notoriedade quando ela se uniu a um dos fundadores do grupo Sex Pistols, ícone musical da década de 1980 com inspiração no movimento punk.

Parte desse grupo de criadores pertencia à elite local em seus paises de origem, como é o caso de Lady Duff Gordon, sobrevivente do naufrágio do Titanic, quando viajava na primeira classe; do suiço Robert Piguet, cujo pai, um banqueiro, desejava que ele atuasse profissionalmente no mercado financeiro; ou de Elsa Schiaparelli, a italiana filha de mãe aristocrata e pai intelectual que se rebelou contra o conservadorismo da família, saiu da Itália para Nova York e finalmente mudou-se para Paris, naturalizando-se francesa por decreto, em 1931.

Renard discorre com encanto sobre a complexa trajetória de Sarkis der Balian. Criador de incriveis modelos de calçados, seus itens expostos na Fashion Mix, ao contrário dos demais, não foram cedidos pelo Palais Galliera, e sim por seus familiares. Nascido em Cilicie, reino da Pequena Armênia, no ano de 1909, ele e sua familia foram deportados sob ordem do governo turco em direção ao sul para serem exterminados. Sarkis sobreviveu, mas se tornou órfão e apátrida, vivendo em um acampamento na cidade de Aleppo, na Síria. Ele foi ao encontro da irmã na Etiópia, porém decidiu mudar-se para Paris com um passaporte libanês, supostamente concedido por estada naquele país por meio de um acordo internacional em que armênios apátridas poderiam obter a nacionalidade do país onde se encontrassem.

A ordem dos blocos e seções, de acordo com Renard, foi inicialmente elaborada conforme a cronologia. Mas, a essa cronologia, deveriam estar relacionadas às escolas que influenciaram a alta-costura parisiense. Assim, as seções teriam a ancoragem de um nome facilmente reconhecido pelo público, como Schiaparelli, que situava o visitante na escola italiana, e Issey Miyake, que abria a seção sobre a escola japonesa. Renard recorda que a década de 1950 foi o tempo da escola francesa, por isso, essa subdivisão se concentrou na "alta-costura cosmopolita", com nomes nem sempre tão familiares ao grande público, como é o caso do egípcio Jean Dessès e o do libanês Rabih Kayrouz.

A narrativa, inicialmente pensada sob o aspecto cronológico, terminou por privilegiar a importância das escolas que influenciaram a moda que se fez em Paris. A primeira seção, por exemplo, que destacou a escola britânica, incluiu nomes como Charles Poynter, que viveu entre 1853 e 1929, e Phoebe Philo, ainda jovem, nascida em 1973. Já entre os contemporâneos, o nome consolidado do tunisiano AzzedineAlaïa, nascido em 1939, divide a seção com a notável jovem holandesa Iris van Herpen, com um pouco mais de 30 anos. 
Quando foi indagado sobre a percepção que teve do público que visitou a Fashion Mix, Samson respondeu:

Bem curiosas. As pessoas estavam muito... muito curiosas, porque esse é um tema que nunca é abordado, a relação da moda com o estrangeiro. A imigração na França e na Europa hoje é, na verdade, o tema, e a moda é sempre reputada como algo frivolo, que não se interessa por essas coisas... a gente fala de luxo etc. Portanto, a moda está ligada à imigração, e o sucesso de Paris como capital da moda está relacionado aos estrangeiros. Eu quero dizer que Paris não seria a capital da moda se não fossem os estrangeiros (tradução livre da autora).

Na construção da narrativa da Fashion Mix, um ponto importante a ser considerado foi o espaço onde foi realizada. Havia a preocupação dos organizadores de contextualizar a exposição na proposta do Musée de l'Histoire de l'Immigration.

A combinação de objetos e textos levou ao visitante a conexão para a construção do conhecimento desejada pelos organizadores. Apoiada em Dias (1994), para quem os objetos são o melhor meio de aproximar a ideia do conhecimento que se deseja oferecer, pois evita a dificuldade e o tédio de longas descrições, entende-se que a força dos objetos (as roupas) privilegiam a moda como tema central. No caso da Fashion Mix, porém, mais do que a força simbólica dos próprios objetos, é o local da realização da exposição um aspecto fundamental a consolidar a narrativa desejada: um museu cujo tema é a imigração, e não a moda.

\section{Museus, roupas, imigração e narrativas}

Os objetos que chegam aos museus operam como signos metonímicos de uma cultura (GONÇALVES, 2007). Há uma representação "visivel" daquilo que está "invisivel" aos olhos do público. 0 diálogo que se estabelece entre objeto e público faz com que este último se aproxime de um tempo ou um espaço distante da sua realidade. No caso da Fashion Mix, a relação metonímica da roupa deveria se dar com o seu criador, um criador não nascido em território francês. Não por acaso, Samson escolheu roupas que fossem "emblemáticas" do trabalho de cada um deles, que os representasse, porém, evidenciando, como na exposição permanente, histórias de vida, biografias diversas.

Dadas as complexidades que envolvem o tema da imigração, sobretudo na Europa atual, a exposição Fashion Mix, por sua narrativa, teve potencial para provocar no visitante algumas reflexões. Dois elementos podem ser destacados e serão desenvolvidos.

0 primeiro, como já mencionado, é o fato de a exposição ter sido montada no Musée de l'Histoire de l'Immigration, e não no Palais Galliera. Isso tornou-se parte da narrativa, uma vez que a proposta do Musée de l'Histoire de l'Immigration tem como especificidade a ideia de dar visibilidade ao papel representado pela imigração na formação da economia e da cultura francesas, provocando, em seu público, uma expectativa acerca desse tema.

A segunda observação trata da relação entre a exposição permanente, Repères, e a temporária, Fashion Mix. Como elas estão posicionadas? Como dialogam entre si e que narrativas estão em jogo, na medida em que, para chegar à Fashion Mix, necessariamente é preciso passar pela Repères?

Pensando na primeira observação sobre a narrativa, ou seja, o espaço onde a exposição Fashion Mix foi realizada, podemos traçar algumas considerações. Gonçalves (2007) posiciona a "nova museologia" como diretriz de instituições afinadas com uma sociedade democrática, diferentemente dos "museus tradicionais". Esses últimos seriam considerados instituições voltadas para si mesmas, 
detentoras de um posicionamento elitista, distanciando-se do cotidiano dos indivíduos. 0 Musée de l'Histoire de l'Immigration busca uma relação de proximidade com a população francesa, bem como com seus visitantes.

Um museu que desafiou o Ministério da Cultura com seu tema, que "poderia ser tudo, menos 'nobre'" (GRUSON, 2011, p. 14), tem sua coleção permanente formada pela contribuição da coletividade, uma aliança, na opinião de Gruson, "pouco habitual para um museu de história e sociedade" (p.14). Essa proximidade, ao que parece, mostrou-se tão verossímil que encorajou um grupo de indocumentados a ocupar o Palais de la Porte Dorée em outubro de 2010 (GRUSON, 2011).

Outros fatores indicativos dessa proximidade podem ser verificados em alguns elementos, a começar pela própria localização do Palais de la Porte Dorée, em um quartier menos sofisticado do que, por exemplo, o do Palais Galliera. Apesar de todos os dispositivos de segurança, bastante presentes, em especial, nos prédios públicos parisienses (mais fortemente após os episódios de atentados contra a redação do Charlie Hebdo e os cafés e outros locais de lazer, em 13 de novembro de 2015), o Palais de la Porte Dorée atua com menor rigor do que outros museus de Paris, nos quais é imprescindivel a exposição ao raio $X$ de todos os pertences dos visitantes. A midiateca é aberta ao público e acessivel a qualquer hora do dia, sem necessidade de agendamento prévio. Essa relação de proximidade é que pode trazer um tema glamouroso, como a alta- costura, para o cotidiano da coletividade, tendo o imigrante que vive na cidade de Paris a possibilidade de identificar um traço comum com aqueles que ali chegaram e fizeram parte da história da moda parisiense.

Gruson (2011), em seu artigo, em cujo título ele já contempla a problemática a qual desenvolve em seguida, se pergunta: um museu pode mudar as representações sobre a imigração? Em um momento em que estereótipos são construídos pela grande mídia audiovisual, e a indústria cultural se estabelece com certa hegemonia, pode um museu "mudar os olhares"? Gruson conclui que essa é uma tarefa complicada, dada a invisibilidade midiática da imigração na França, especialmente no que se refere às suas contribuições. 0 esforço da instituição, portanto, não é irrelevante, tampouco é definitivo. As peculiaridades, em especial o cenário político que emoldura a concepção do museu, já exposto neste texto, respondem, portanto, em parte, ao questionamento do autor.

A segunda observação, em relação à exposição permanente Repères, a Fashion Mix parece conduzir o visitante a conhecer um perfil diferente de imigrante, qual seja aquele sujeito que empreendeu um deslocamento e se destacou em um campo privilegiado da indústria francesa. Para além do aspecto econômico envolvido na indústria da moda, o contato com a alta-costura aporta aos sujeitos distinção social no sentido dado por Bourdieu (2007), tanto para os consumidores quanto para os produtores, mas, sobretudo, para os que se destacam em seu processo de criação.

A exposição permanente está localizada no caminho para chegar ao salão das exposições temporárias, onde foi realizada a Fashion Mix. Nesse caso, é inevitável que parte do acervo permanente seja observada pelo visitante ainda antes de ele alcançar a exposição temporária. Assim, os olhos do público, ainda fixados na profusão de imagens de imigrantes em condições desfavoráveis, encontra na Fashion Mix algumas nuances das trajetórias dos criadores ali apresentados. Porém, a despeito das biografias que se desenrolaram nos textos ao longo da mostra Fashion Mix é a participação no privilegiado campo da moda que os diferencia do perfil desprovido e desfavorecido. 
Iniciar com Worth se revelou uma escolha emblemática. Se a construção de uma imagem de sofisticação parisiense remonta aos tempos do reinado de Luis XIV, não podemos esquecer que, desde então, o papel do estrangeiro como artífice do luxo ganha importância entre os cortesãos. 0 rei, afinal, delegou a seu ministro Colbert a tarefa de encontrar os melhores artesãos europeus em cada uma das suas especializações e levá-los para Versalhes. Mas o século XIX, periodo em que se desenvolve a construção da ideia de estado-nação, marca também a entrada de Worth em território francês, em um campo que mais tarde seria legitimado como parte da identidade dessa nação, a moda. Noiriel (2015) assinala como um dos marcos da construção da concepção francesa de nação a obra do filósofo Jules Michelet, que desenha a oposição "nós e eles" no século XIX. Diante desse cenário, não há como nos distanciar das circunstâncias históricas que evidenciam ainda mais a importância do desafio enfrentado por um criador estrangeiro, como Worth, na moda francesa no século XIX.

\section{Considerações finais}

A proposta deste artigo foi analisar a exposição Fashion Mix do ponto de vista de sua narrativa, considerando a articulação entre a moda e a imigração de criadores de moda para Paris. Retomando os três aspectos definidos por Jordanova (1989), podemos repassar rapidamente os significados que os organizadores desejaram transmitir.

0 primeiro deles, o olhar encontra, ao fim, na própria instituição onde foi realizada a exposição Fashion Mix, o Musée de l'Histoire de l'Immigration, uma construção especifica, baseada nas expectativas de um público determinado. Além disso, há ainda um percurso que se dá na relação entre o visitante e o objeto, como força expressiva da narrativa. Nesse caso, as roupas e a representação do "invisivel" que elas encerram. Mais do que um tempo inscrito em seus modelos e estado de conservação, a marca dos seus criadores (por sua origem estrangeira) foi a intenção narrativa das escolhas exibidas na exposição.

0 segundo aspecto relacionado por Jordanova (1989) é a técnica narrativa. A Fashion Mix se vale de um conjunto de objetos, entre roupas, documentos e fotografias, que não dispensa quadros explicativos, até porque as histórias e a valorização da condição de imigrante de cada criador são requeridas pelos organizadores. A organização da Fashion Mix, apesar de contar com uma comunicação que privilegia elementos que remetem ao tema da moda, procura mostrar que este, apesar de sedutor, não é central. A comunicação está embasada no cartaz da exposição, em que há um modelo em uma passarela envergando uma criação de Yohji Yamamoto. A criação de Yamamoto sugere traços de sua etnia, tal como Samson os reconhece na obra de Kawakubo. Mas essa leitura, que remete à roupa pela etnia de Yamamoto, seria possivel se se tratasse de uma exposição em um museu sobre moda? 0 público perceberia esses traços? 0 material empírico não nos permite desenvolver essas questões, mas é importante que as tenhamos em mente.

A classificação, terceiro aspecto elencado por Jordanova (1989), é algo mais complexo. No caso da Fashion Mix, ela tem na equação criadores imigrados e suas histórias de vida, a disponibilidade de peças em condições de exibição e a narrativa desejada, elementos a pesar na "leitura" que se desejou proporcionar ao visitante. Nomes conhecidos do grande público foram escolhidos para representar cada seção e cada escola que influenciou a moda parisiense, pensando exatamente nas expectativas de alguém "não iniciado" no campo da moda, nas palavras de Samson. Esses elementos se misturaram a uma perspectiva cronológica, inicialmente planejada pela organização.

A exposição, ao fim, oferece maior clareza sobre a construção do epiteto "Paris, capital da moda". Essa "joia da economia francesa", como descreve Renard, 
tem, nos criadores estrangeiros, um papel de grande importância para operar na relação dialógica na qual essas mãos criativas também são valorizadas na medida em que atuam na capital da moda.

Na Fashion Mix, criadores com histórias de vida tão díspares estão reunidos no sofisticado campo da moda da alta-costura. Há os que foram apátridas, como Sarkis der Balian, nobres, como o casal Yusupov, de origem aristocrática, como Schiaparelli, ou refugiados, como Balenciaga. Todos se encontraram para fazer de Paris, a capital da moda. Em outro importante encontro proporcionado pela Fashion Mix, a "frivolidade" da moda fica face a face com o tema "problemático" da imigração. Por fim, podemos dizer que a capital da moda é um mundo cosmopolita e plural, sinalizando que a moda é um fenômeno que ultrapassa as fronteiras.

[Recebido em: 10/03/2016]

[Aprovado em: 19/06/2016]

\section{NOTAS}

[1] Pesquisa realizada com o apoio financeiro da CAPES (Coordenação de Aperfeiçoamento de Pessoal de Nível Superior), processo no. 1267/14-0. CAPES Foundation, Ministry of Education of Brazil, Brasilia/DF 70040-020, Brazil e o apoio institucional da EHESS (Écoledes Hautes Étudesen Sciences Sociales) - Paris, sob a direção da Profa. Dra. Mônica Raisa Schpun. Jan./2015-Jan./2016.

[2] Fashion Mix: Moda daqui, criadores de fora (Tradução livre da autora).

${ }^{[3]}$ Azzi (2010) destacou o acervo do Palais Galliera como sendo o que detém o maior número de peças. Em seu livro, lançado em 2010, ela menciona que a reserva técnica contava com cerca de 90000 itens.

${ }^{[4]}$ A cidade de Paris é dividida em 20 arrondissements, palavra que pode ser traduzida como "bairro ou "distrito".

${ }^{[5]} \mathrm{A}$ história da imigração (na França) é também a história da França" (tradução livre da autora)

[6] Ver: http://www.france24.com/fr/20141215-hollande-inauguration-controverse-musee-histoire-immigrationchirac-sarkozy-polemiquehttp://www.france24.com/fr/20141215-hollande-inauguration-controverse-museehistoire-immigration-chirac-sarkozy-polemique

http://www.francetvinfo.fr/politique/pourquoi-il-a-fallu-attendre-sept-ans-avant-d-inaugurer-la-citenationale-de-I-histoire-de-I-immigration_772935.htmlhttp://www.francetvinfo.fr/politique/pourquoi-il-afallu-attendre-sept-ans-avant-d-inaugurer-la-cite-nationale-de-I-histoire-de-l-immigration_772935.html

http://www.francetvinfo.fr/politique/pourquoi-il-a-fallu-attendre-sept-ans-avant-d-inaugurer-la-citenationale-de-I-histoire-de-I-immigration_772935.html

${ }^{[7]}$ Com o objetivo de estimular a indústria local, a França realizou a sua primeira exposição nacional denominada Exposition desProduitsde l'Industrie em 1798, apenas alguns anos depois do início da Primeira República (1792). Mais tarde, em 1851, os ingleses, com o intuito de internacionalizar o evento inauguraram a fase das Exposições Internacionais (GreatExhibitionofthe Works oflndustryofallNations), construindo o famoso Palácio de Cristal no Hyde Park (Lopes, 2007).

[8] "A frivolidade é difundida na França, e em Paris mais do que em qualquer outra parte" (tradução livre da autora).

${ }^{[9]}$ A metodologia empregada pela agência para determinar o ranking de "capital da moda" está em sua página na web: http://www.languagemonitor.com/category/fashion/fashion-capitals/page/3/: a medição é feita através de um algoritmo que mede a presença na internet. "Each July, the Global Language Monitor ranksthe Top Fashion CitiesoftheYearrankedby Internet presence in a global survey". 


\section{REFERÊNCIAS}

AZZI, Christine Ferreira. Vitrines e coleções: quando a moda encontra o museu. Rio de Janeiro: Memória Visual, 2010

BARTHIER, Delphine. Paris, capitale de la mode. Construction de savoir-faire et remise en question du mythe de la Ville-Lumière. Mémoire ecrit sous la direction de Claire Toupin-Guyot. Paris: SciencePo Rennes, 2013/14

BENJAMIN, Walter. Paris: capital of the nineteenth century. In.: Perspecta, vol. 12,1969. MIT Press, University of Yale, pp. 163-172.

BOURDIEU, Pierre. A distinção: crítica social do julgamento. São Paulo: Edusp, 2007.

DEJEAN, Joan. A essência do estilo: como os franceses inventaram a alta-costura, a gastronomia, os cafés chiques, o estilo, a sofisticação e o glamour. Rio de Janeiro: CivilizaçãoBrasileira, 2010.

DIAS, N. Looking at objects: memory, knowledge in nineteenth-century ethnographic displays. In: ROBERTSON, G. et al(Orgs.).Traveller's tales: narratives of home and displacement. Routledge, 1994 pp. 164-176.

GONÇALVES, José Reginaldo Santos. Antropologia dos objetos: coleções, museus e patrimônios. Rio de Janeiro: Coleção Museus e Patrimônios, 2007.

GREEN, Nancy. Les americains de Paris: hommes d'affaires, comtesses e jeunes oisifs 1880-1941. Paris: Gallimard, 1994.

GRUNSON, Luc. Un musée peut-il changer les representations sur l'immigration? In.: Revue Hommes \& Migrations. Dossiê: L'immigration dans les musées: une comparaison international, n. 1293, set./out., 2011.

JORDANOVA, L Objects of knowledge. In:VERGO, P. (Org.). The new museology Londres: Reaktion Books, 1989. pp. 22-40.

LAVER, James. A roupa e a moda: uma história concisa. São Paulo: Companhia das Letras, 1989.

LIPOVETSKY, Gilles. 0 império do efêmero: a moda e seu destino nas sociedades modernas. São Paulo: Companhia da Letras, 1989.

LOPES, Ana Patricia 0. Exposições universais parisienses oitocentistas. Prova final Licenciatura em Arquitetura. fARQ, FETUC. Coimbra, 2007.

NOIRIEL, Gérard. État, nation et immigration. Paris: Gallimard, 2005.

Qu'est-ce qu'une nation?. Paris: Bayard, 2015.

POINSOT, Marie. Paris et la mode, une relation capitale? Entretien avec Olivier Saillard, directeur du Palais Galliera, Musée de la Mode de la Ville de Paris, et commissaire general de l'exposition Fashion Mix au Palais de la Porte Dorée. In: Revue Hommes \&t Migrations. Dossiê: Fashion Mix, n. 1310, abr.,maio, jun., 2015.

TODD, Emmanuel. Le destin des immigrés. Paris: Editions du Seuil, 1994.

WILLIAMS, Rosalind. Dream Worlds:mass consumption in late nineteenth-Century-France. Berkeley: University of California Press, 1982.

\section{MATERIAL DA IMPRENSA FRANCESA:}

Nous ne pouvons rester silencieux. Gérard Noiriel explique sa décision de quitter la future Cité de I'Histoire de l'Immigration. Libération, 24 maio 2007.

LECLÉRE, Thierry. Demissions et crise d'identité a la future Cité de l'Immigration. Télérama, 6 jun. 2007.

PĖNE, Clémence. Immigration: une cité sous tension. L'Express, 16 ago. 2007. 